Abstract

\title{
Damage and Stress Detection (Self-Sensing) in Concrete with Multi-Walled Carbon Nanotubes ${ }^{\dagger}$
}

\author{
Jan Suchorzewski, Miguel Prieto, Urs Mueller * and Katarina Malaga \\ RISE Research Institutes of Sweden, RISE Built environment, Brinellgatan 4, 50115 Borås, Sweden; \\ jan.suchorzewski@ri.se (J.S.); miguel.prieto@ri.se (M.P.); katarina.malaga@ri.se (K.M.) \\ * Correspondence: urs.mueller@ri.se \\ + Presented at the 1st International Conference on Smart Materials for Sustainable Construction-SMASCO \\ 2019, Luleå, Sweden, 10-12 December 2019.
}

Published: 18 November 2019

\begin{abstract}
Within EU project LightCoce (Building an Ecosystem for the upscaling of lightweight multi-functional concrete and ceramic materials and structures), RISE will be running a Pilot Line to allow the design and development of materials, elements of Cellular Lightweight Concrete (CLC) and/or lightweight composite elements with improved functionalities. One of these functionalities is self-sensing (damage and stress detection), achieved by reducing the natural concrete's resistance with incorporation of the multi-walled carbon nanotubes (MWCNTs). By applying a small electric current in the outer electrodes attached to the concrete and measuring voltage on the inner electrodes the resistivity of the material can be easily calculated. The resistivity changes may indicate cracking and changing stress levels. In our study concrete was enhanced with various amounts of MWCNTs and tested in cyclic compression. The change of stress levels was clearly visible on the resistivity changes. After that, ultrahigh-performance concrete (UHPC) panels with two types of textile reinforcement (GFRP and CFRP) were tested in cyclic 4-point bending to investigate concretes sensitivity for multiple cracking. The resistivity measurement was able to capture multiple discrete cracks and the material degradation at micro-level due to fatigue.
\end{abstract}

Keywords: self-sensing; concrete; MWCNTs

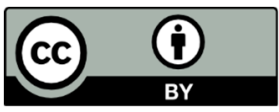

(C) 2019 by the authors. Licensee MDPI, Basel, Switzerland. This article is an open access article distributed under the terms and conditions of the Creative Commons Attribution (CC BY) license (http://creativecommons.org/licenses/by/4.0/). 